\title{
Oridonin induces apoptosis and cell cycle arrest of gallbladder cancer cells via the mitochondrial pathway
}

Runfa Bao ${ }^{1,2+}$, Yijun Shu ${ }^{1,2+}$, Xiangsong Wu ${ }^{1,2}$, Hao Weng ${ }^{1,2}$, Qian Ding ${ }^{1,2}$, Yang Cao ${ }^{1,2}$, Maolan Li ${ }^{1,2}$, Jiasheng Mu ${ }^{1,2}$,

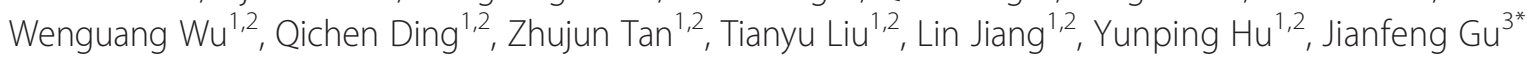
and Yingbin Liu ${ }^{1,2^{*}}$

\begin{abstract}
Background: Gallbladder cancer is the most frequent malignancy of the bile duct with high aggressive and extremely poor prognosis. The main objective of the paper was to investigate the inhibitory effects of oridonin, a diterpenoid isolated from Rabdosia rubescens, on gallbladder cancer both in vitro and in vivo and to explore the mechanisms underlying oridonin-induced apoptosis and cell cycle arrest.

Methods: The anti-tumor activity of oridonin on SGC996 and NOZ cells was assessed by the MTT and colony forming assays. Cell cycle changes were detected by flow cytometric analysis. Apoptosis was detected by annexin V/PI double-staining and Hoechst 33342 staining assays. Loss of mitochondrial membrane potential was observed by Rhodamine 123 staining. The in vivo efficacy of oridonin was evaluated using a NOZ xenograft model in athymic nude mice. The expression of cell cycle- and apoptosis-related proteins in vitro and in vivo was analyzed by western blot analysis. Activation of caspases (caspase- $3,-8$ and -9 ) was measured by caspases activity assay.

Results: Oridonin induced potent growth inhibition, S-phase arrest, apoptosis, and colony-forming inhibition in SGC996 and NOZ cells in a dose-dependent manner. Intraperitoneal injection of oridonin (5, 10, or 15 mg/kg) for 3 weeks significantly inhibited the growth of $\mathrm{NOZ}$ xenografts in athymic nude mice. We demonstrated that oridonin regulated cell cycle-related proteins in response to S-phase arrest by western blot analysis. In contrast, we observed inhibition of NF-KB nuclear translocation and an increase Bax/Bcl-2 ratio accompanied by activated caspase-3, caspase-9 and PARP-1 cleavage after treatment with oridonin, which indicate that the mitochondrial pathway is involved in oridonin-mediated apoptosis.

Conclusions: Oridonin possesses potent anti-gallbladder cancer activities that correlate with regulation of the mitochondrial pathway, which is critical for apoptosis and S-phase arrest. Therefore, oridonin has potential as a novel anti-tumor therapy for the treatment of gallbladder cancer.
\end{abstract}

Keywords: Oridonin, Gallbladder cancer, Apoptosis, Cell cycle arrest, Mitochondrial pathway

\footnotetext{
* Correspondence: jscsgjf@sina.cn; liuybphd@126.com

${ }^{\dagger}$ Equal contributors

${ }^{3}$ Department of General Surgery, Changshu Hospital, Affiliated to Suzhou

University, No.1 Shuyuan Road, Changshu 215500, China

'Institute of Biliary Tract Disease, Shanghai Jiao Tong University School of

Medicine, No. 1665 Kongjiang Road, Shanghai 200092, China

Full list of author information is available at the end of the article
} 


\section{Background}

Gallbladder cancer, the most frequent malignancy of the bile duct, is a highly aggressive, lethal neoplasm that is associated with high mortality and extremely poor prognosis [1,2]. Despite recent advances in diagnostic and therapeutic approaches, the 5-year survival rate is generally $13 \%-30 \%$ [3]. Because of the absence of specific symptoms and signs, it is usually detected at an advanced stage [4]. Surgical resection is the only potentially curative therapy for gallbladder cancer [5]. Moreover, the majority of patients have frequent recurrences following surgery and unsatisfactory results after chemotherapy or radiotherapy [6]. Therefore, novel effective therapeutic drugs are urgently needed for this deadly disease.

Oridonin (Figure 1A), an active diterpenoid compound purified from the Chinese herb Rabdosia rubescens, has been reported to have various pharmacological and physiological effects, such as anti-inflammatory, anti-bacterial, and even anti-tumor effects [7]. Studies have shown that oridonin induces apoptosis in cells derived from a variety of cancers, including breast cancer, hepatocellular carcinoma, colorectal cancer, gastric cancer, and pancreatic cancer [8-12]. However, ordonin has very little effect on normal human cells such as lymphoid cells and fibroblasts [13,14]. In recent years, oridonin has attracted more attention because it stimulates cell cycle arrest and apoptosis in a wide variety of tumors both in vivo and in vitro. Numerous proteins and pathways have been shown to regulate oridoninmediated apoptosis, including the cysteine-dependent aspartate-specific proteases (caspase) family, the Bcl-2 family, the mitogen-activated protein kinase (MAPK) family, the nuclear factor-kappaB (NF-kB), p53, and phosphoinositide 3-kinase (PI3K) signal transduction pathways

A

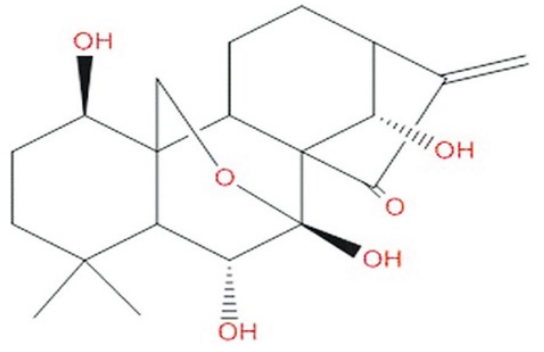

\section{Oridonin}

B

$24 \mathrm{~h}$

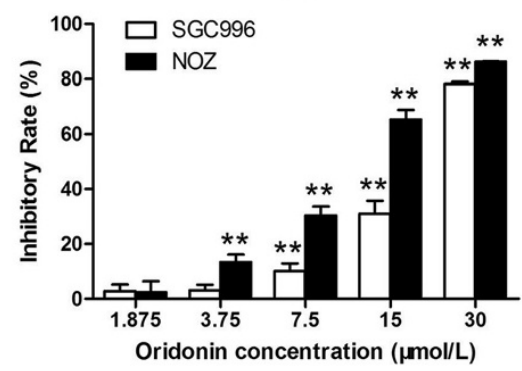

$72 \mathrm{~h}$

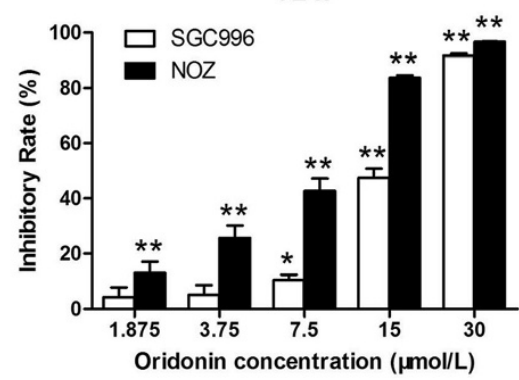

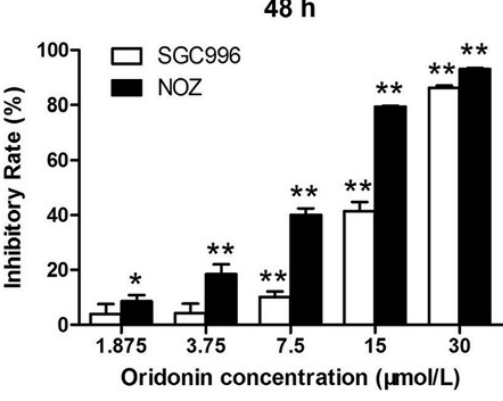

C

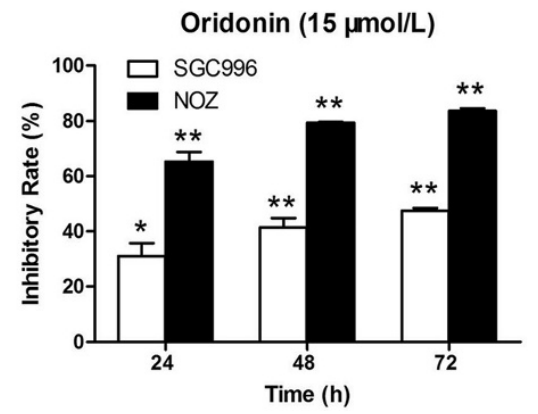

Figure 1 Oridonin inhibits the proliferation of gallbladder cancer cells. (A) Chemical structure of oridonin. (B) SGC996 and NOZ cells were treated with various concentrations of oridonin or vehicle for 24,48 , and 72 h. (C) Cells were incubated with $15 \mu \mathrm{mol} / \mathrm{L}$ oridonin for various time periods. Effects of oridonin on cell proliferation were determined by the MTT assay. Data are expressed as the mean \pm SD $(n=5)$. The data were obtained from 3 independent experiments. ${ }^{*} P<0.05,{ }^{*} P<0.01$ vs. the control group. 
$[12,13,15,16]$. However, systematic studies on how oridonin affects gallbladder cancer have not been reported.

In this study, we investigated whether oridonin induced growth inhibition, cell cycle arrest in gallbladder cancer cells in vitro and in vivo, and we explored the possible mechanisms of action, which could provide experimental evidence for the potential application of oridonin as a new natural anti-tumor medicine for gallbladder cancer.

\section{Methods}

\section{Materials}

Oridonin was purchased from Sigma-Aldrich (St. Louis, MO, USA). For in vitro studies, oridonin was dissolved in dimethyl sulfoxide (DMSO) to create a stock solution $(0.1 \mathrm{~mol} / \mathrm{L})$, which was stored at $-20^{\circ} \mathrm{C}$. To prepare working solutions, the stock solution was further diluted with culture media to yield the desired oridonin concentration. Control cells were treated with an equal volume of vehicle. The DMSO concentration was kept below $0.1 \%$ in cell culture and did not have any detectable effect on cell growth or cell death.

3-[4,5-dimethylthiazol-2-yl]-2,5-diphenyl-tetrazolium bromide (MTT), Hoechst 33342, annexin V-FITC, propidium iodide (PI), and Rhodamine 123 were purchased from Sigma Chemical Co. (St. Louis, MO, USA). Primary antibodies against caspase-3, caspase-9, NF-kB, Bax, Bcl-2, PARP-1, cytochrome $c$, $\beta$-actin, and secondary antibodies (goat-anti-rabbit or goat-anti-mouse) were purchased from Cell Signaling Technology (Danvers, MA, USA). Antibodies against cyclin A, cyclin B1, and cyclin D1 were purchased from Epitomics (Burlingame, CA, USA).

\section{Cell lines and cell culture}

The human gallbladder cancer cell lines SGC996 and NOZ were purchased from the Cell Bank of Type Culture Collection of Chinese Academy of Sciences (Shanghai, China). SGC996 cells were cultured in Rosewell Park Memorial Institute (RPMI) 1640 medium (Gibco, USA). NOZ cells were cultured in William's medium (Gibco). The media for both cell lines were supplemented with $10 \%$ fetal bovine serum (Gibco), $100 \mu \mathrm{g} / \mathrm{mL}$ streptomycin, and $100 \mathrm{U} / \mathrm{mL}$ penicillin (Hyclone, USA) and maintained at $37^{\circ} \mathrm{C}$ in a humidified atmosphere with $5 \% \mathrm{CO}_{2}$.

\section{Cell viability assay}

The viability of cells treated with oridonin was measured by the MTT assay. During the logarithmic growth phase, cells were collected and seeded in 96-well plates at a density of $5 \times 10^{3}$ cells/well and cultured. After $12 \mathrm{~h}$ of incubation, the cells were treated with oridonin ( 0 , $1.875,3.75,7.5,15$, and $30 \mu \mathrm{mol} / \mathrm{L}$ ) for 24,48 , and $72 \mathrm{~h}$. After treatment, $20 \mu \mathrm{L}$ of MTT solution $(5 \mathrm{mg} / \mathrm{mL}$ ) was added to each well and the cells were then incubated at $37^{\circ} \mathrm{C}$ for $4 \mathrm{~h}$. The culture medium was then replaced with $100 \mu \mathrm{L}$ of DMSO. The absorbance of the solution at $490 \mathrm{~nm}$ was measured with a microplate reader (Bio-Tek, USA). The results represent the average of 5 parallel samples. The cell inhibitory rate was calculated as follows: Inhibitory rate $(\%)=\left(\mathrm{A}_{490}\right.$ control $-\mathrm{A}_{490}$ sample $)$ / $\left(\mathrm{A}_{490 \text { control }}-\mathrm{A}_{490 \text { blank }}\right) \times 100 \%$.

\section{Colony forming assay}

SGC996 and NOZ cells were plated into a 6-well culture plate (500 cells/well) and allowed to adhere for $10 \mathrm{~h}$ before treatment. After adherence, cells were treated with oridonin $(0.75,1.5$, and $3 \mu \mathrm{mol} / \mathrm{L})$. After $48 \mathrm{~h}$, the oridonin-containing medium was removed, and the cells were allowed to form colonies in complete medium for 14 days. Then, the colonies were fixed with a solution of acetic acid and methanol (1:3) for $15 \mathrm{~min}$, stained with $5 \%$ Giemsa (Sigma-Aldrich) for $30 \mathrm{~min}$, and counted manually. Digital images were taken of stained single clones observed under a microscope (Leica, Germany).

\section{Cell cycle analysis by flow cytometry}

Cells were treated with oridonin $(7.5,15$, and $30 \mu \mathrm{mol} / \mathrm{L})$ for $48 \mathrm{~h}$. Both floating and adherent cells were collected and washed with cold phosphate buffered saline (PBS) and fixed with $70 \%$ ethanol overnight at $4^{\circ} \mathrm{C}$. Cells were then treated with staining buffer (PBS containing $1 \mathrm{mg} / \mathrm{mL}$ PI and $10 \mathrm{mg} / \mathrm{mL}$ RNase A; Sigma-Aldrich) at $37^{\circ} \mathrm{C}$ in the dark for $30 \mathrm{~min}$. The samples were analyzed with a flow cytometer (BD, San Diego, CA, USA).

\section{Annexin V/PI staining assay for apoptosis}

The cells were treated with oridonin (7.5, 15, and $30 \mu \mathrm{mol} / \mathrm{L}$ ) for $48 \mathrm{~h}$. After washing twice with cold PBS, the cells were resuspended at a density of $1 \times 10^{6}$ cells/ $\mathrm{mL}$. Then, $100 \mu \mathrm{L}$ of binding buffer containing $2.5 \mu \mathrm{L}$ of annexin V-FITC and $1 \mu \mathrm{L}$ of $100 \mu \mathrm{g} / \mathrm{mL}$ PI was added to these cells and incubated for $30 \mathrm{~min}$ in the dark. Finally, the samples were analyzed by a flow cytometer (BD).

\section{Observation of morphological changes with Hoechst 33342 staining}

After treatment with oridonin $(7.5,15$, and $30 \mu \mathrm{mol} / \mathrm{L})$ for $48 \mathrm{~h}$, the cells were washed in PBS and fixed with methanol:acetic acid (3:1) at room temperature for $15 \mathrm{~min}$. Then, the cells were washed in PBS and stained with $5 \mu \mathrm{g} / \mathrm{mL}$ Hoechst 33342 for $10 \mathrm{~min}$ at $37^{\circ} \mathrm{C}$. Finally, the cells were washed with PBS and observed under a fluorescence microscope (Leica, Germany).

\section{Detection of mitochondrial membrane potential $(\Delta \Psi \mathrm{m})$ variation by flow cytometry}

$\Delta \Psi \mathrm{m}$ was analyzed by flow cytometry following Rhodamine 123 staining [17]. After treatment with oridonin (7.5, 15, 
and $30 \mu \mathrm{mol} / \mathrm{L}$ ) for $48 \mathrm{~h}$, the culture medium was removed and the cells were washed with PBS twice and then stained in Rhodamine 123 staining solution $(5 \mu \mathrm{g} / \mathrm{mL})$ at $37^{\circ} \mathrm{C}$ for $20-30 \mathrm{~min}$. The samples were analyzed by using a flow cytometer (BD).

\section{Western blot analysis}

The cells were incubated with oridonin $(7.5,15,30 \mu \mathrm{mol} / \mathrm{L})$ for $48 \mathrm{~h}$, and then the adherent and floating cells were harvested, washed twice with ice-cold PBS, and lysed in RIPA buffer (Beyotime Institute of Biotechnology, Beijing, China) and protease inhibitor (Roche Applied Science, Indianapolis, IN, USA) at $4^{\circ} \mathrm{C}$ for $5 \mathrm{~min}$. After centrifugation at $14,000 \times g$ for $5 \mathrm{~min}$, the protein content of the supernatant was determined by the bicinchoninic acid (BCA) assay kit (Beyotime) according to the manufacturer's instructions. The protein lysates ( $40 \mu \mathrm{g} / \mathrm{lane})$ were separated by $10 \%$ SDS-PAGE and blotted onto nitrocellulose membranes (Millipore, Bedford, MA, USA). Each membrane was blocked with $5 \%$ skim milk, and then incubated with the indicated primary antibodies against caspase-3, caspase-9, NF- $\mathrm{B}$, Bax, Bcl-2, PARP-1, cytochrome $c$, cyclin A, cyclin $\mathrm{B} 1$, cyclin D1, and $\beta$-actin overnight at $4^{\circ} \mathrm{C}$. Subsequently, the membrane was incubated with the secondary antibodies (HRP-conjugated goat anti-rabbit or goat anti-mouse IgG) for $1 \mathrm{~h}$ at room temperature and the formed immunocomplex was visualized by using a Gel Doc 2000 (BioRad, USA). The mitochondrial and cytosol fractions were extracted using the mitochondria extraction kit (Beyotime).

\section{Caspases activity assay}

Cells $\left(5 \times 10^{5} /\right.$ dish) were seeded in $10 \mathrm{~cm}$ dishes and treated with 7.5, 15 and $30 \mu \mathrm{mol} / \mathrm{L}$ of oridonn for $48 \mathrm{~h}$. After different treatments, cells were collected, washed three times with PBS and resuspended in Cell lysates buffer (25 mM Tris - $\mathrm{HCl}, \mathrm{pH} 7.5,20 \mathrm{mM} \mathrm{MgCl}$, and $150 \mathrm{mM} \mathrm{NaCl}, 1 \%$ Triton X-100, $25 \mu \mathrm{g} / \mathrm{ml}$ leupeptin, and $25 \mu \mathrm{g} / \mathrm{ml}$ aprotinin) for $15 \mathrm{~min}$ on ice. Lysates were centrifuged at $16,000 \times \mathrm{g}$ for $15 \mathrm{~min}$, the supernatants collected and protein concentration determined by Bradford Protein Assay Kit (Beyotime, China). Cellular extracts $(30 \mu \mathrm{g})$ were then incubated in a 96-well microtitre plate with 20 ng Ac-DEVD-pNA, Ac-IETD-pNA and Ac-LEHDpNA (Beyotime) for $2 \mathrm{~h}$ at $37^{\circ} \mathrm{C}$. Caspases activity was measured by cleavage of the Ac-DEVD-pNA, Ac-IETDpNA and Ac-LEHD-pNA substrate to pNA, the absorbance of which was measured at $405 \mathrm{~nm}$. Relative caspase activity was calculated as a ratio of emission of treated cells to untreated cells.

\section{Experimental animals}

Male athymic nude mice (4-6 weeks old with an initial body weight of $20 \pm 2$ g) were obtained from Shanghai SLAC Laboratory Animal Co., Ltd. (Shanghai, China). The animals were acclimatized at a temperature of $25^{\circ} \mathrm{C} \pm 2^{\circ} \mathrm{C}$ and a relative humidity of $70 \% \pm 5 \%$ under natural light/ dark conditions for 1 week with ad libitum access food and water. All animal treatments were performed in strict accordance with international ethical guidelines and the National Institutes of Health Guide for the Care and Use of Laboratory Animals. The animal experiments were approved by the Institutional Animal Care and Use Committee of Shanghai Jiao Tong University.

\section{In vivo tumor xenograft study}

NOZ cells in log-phase growth were resuspended in serum-free culture medium (at a density of $1 \times 10^{6}$ cells in $0.2 \mathrm{~mL}$ ), and then tumor xenografts were established by subcutaneous inoculation of these NOZ cells into the right flank of nude mice. Twenty-four hours postinoculation, the mice were randomly divided into 4 groups (10 mice/group). One group was administered vehicle (10\% DMSO and 90\% PBS) intraperitoneally (IP) and the others were administered oridonin $(5,10$, and $15 \mathrm{mg} / \mathrm{kg}$ ) IP in a volume of $0.2 \mathrm{~mL}$ every 2 days for up to 20 days. Tumor volume was measured using calipers and estimated according to the following formula: tumor volume $\left(\mathrm{mm}^{3}\right)=\left(\mathrm{L} \times \mathrm{W}^{2}\right) / 2$, where $\mathrm{L}$ and $\mathrm{W}$ represent the length and width of the tumor, respectively. On day 21, the animals were sacrificed, and the tumor tissue was removed and weighed. Xenograft tumors in control mice and in mice treated with $15 \mathrm{mg} / \mathrm{kg}$ oridonin were harvested and cut into sections for western blot analysis.

\section{Western blot analysis of tumor tissues}

Protein was routinely extracted from tumor tissues using RIPA buffer. Protein concentration was measured using a BCA assay kit (Beyotime). Tumor tissue extracts containing $80 \mu \mathrm{g}$ of protein were separated by $10 \%$ SDS-PAGE, and then the resolved proteins were transferred to nitrocellulose membranes. After blocking with 5\% skim milk, the membranes were incubated with individual primary antibodies overnight at $4^{\circ} \mathrm{C}$, and the bound antibodies were detected with an HRP-conjugated goat anti-rabbit or goat anti-mouse IgG for $1 \mathrm{~h}$. The formed immunocomplexes were visualized by using the Gel Doc 2000.

\section{Statistical analysis}

All data and results were confirmed in at least 3 independent experiments. Data are expressed as the means \pm SD. Differences between 2 sample means were assessed by Student's $t$-test using SPSS v19.0 software (IBM Corporation). A $P$ value of less 0.05 was considered statistically significant. 


\section{Results}

Oridonin inhibits the proliferation of gallbladder cancer cells To investigate the effect of oridonin on the proliferation of cells, SGC996 and NOZ cells were treated with various concentrations of oridonin and cell proliferation was detected by the MTT assay. Oridonin exhibited a potent cytotoxic effect on SGC996 and NOZ cells in a timeand dose-dependent manner (Figure 1). These 2 tumor cell lines showed different sensitivity to oridonin. NOZ cells were more sensitive to oridonin than SGC996 cells. At $30 \mu \mathrm{mol} / \mathrm{L}$ oridonin, the growth of SGC996 and NOZ cells was almost completely inhibited. The ability of gallbladder cancer cells to form colonies in the presence of oridonin was assessed by the flat plate colony forming assay (Figure 2A). The assay results showed that oridonin induced a dose-dependent decrease in colony formation. Moreover, statistical analysis demonstrated that the mean sizes of the colonies in the control were larger than those in the oridonin-treated group (Figure $2 \mathrm{~B}$ ). The results indicate that oridonin may have a long-term effect on the proliferation of gallbladder cancer cells.

\section{Oridonin induces cell cycle arrest at S-phase in gallbladder cancer cells}

To determine whether the effects of oridonin on the proliferation of gallbladder cancer cells are mediated by inhibition of cell cycle progression, the cell cycle phases of treated cells were analyzed by flow cytometry. Oridoninmediated changes in the cell cycle of SGC996 and NOZ

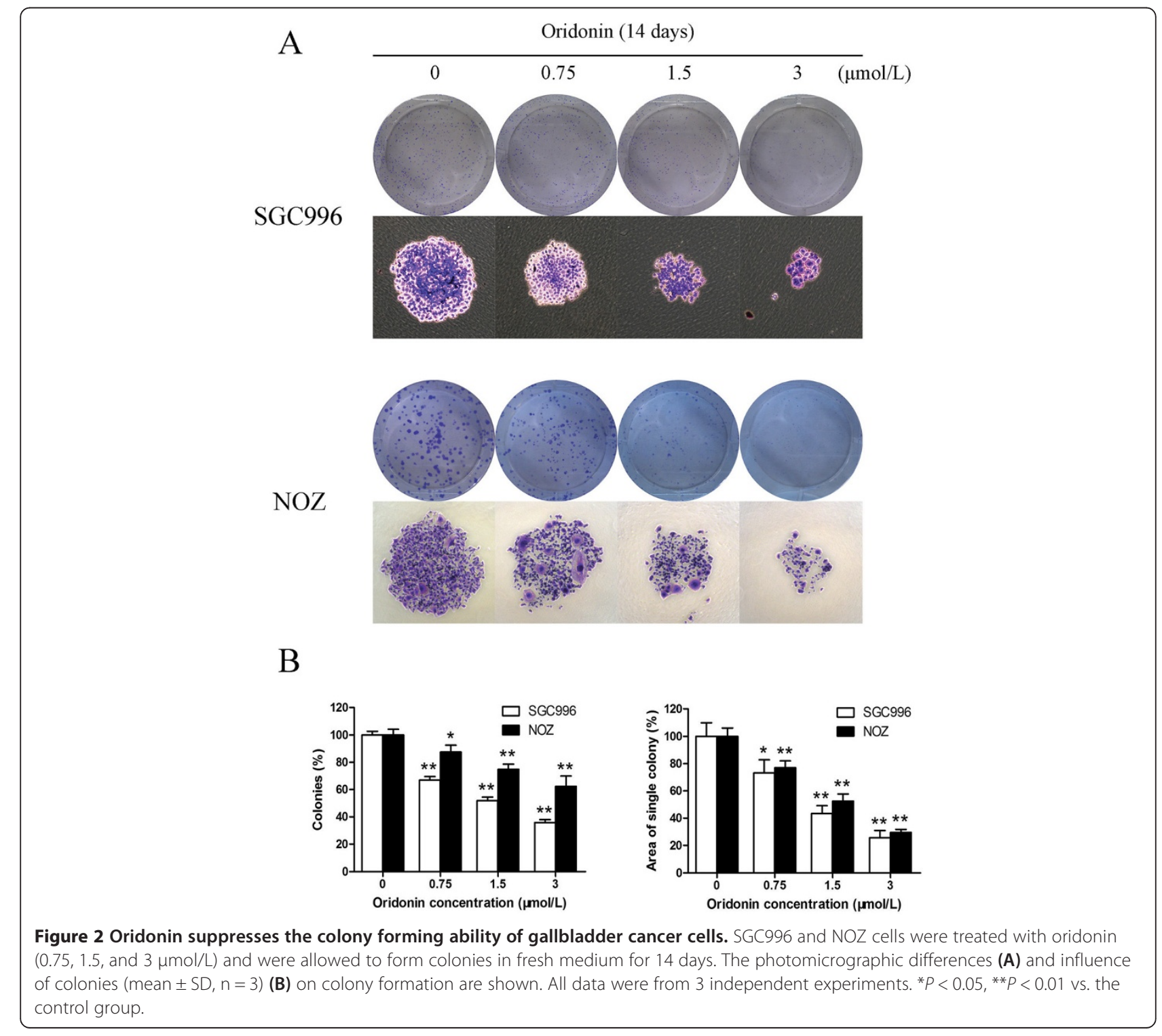


cells are shown in Figure 3A. After treatment with oridonin for $48 \mathrm{~h}$, the percentage of G0/G1-phase cells dramatically decreased (from $74.86 \%$ to $48.90 \%$ for SGC996 cells and from $53.80 \%$ to $23.91 \%$ for NOZ cells), whereas the percentage of cells in S-phase dramatically increased (from $19.22 \%$ to $39.80 \%$ for SGC996 cells and from $35.76 \%$ to 74.02\% for NOZ cells) compared to control cells. Higher oridonin concentrations had additional effects on the distribution of gallbladder cancer cells in the cell cycle. These results indicate that oridonin induced S-phase arrest in a dose-dependent manner.

We also assessed the levels of the G0/G1-related protein cyclin D1, the S-related protein cyclin $\mathrm{A}$, and the G2/M-related protein cyclin B1 by western blot analysis in SGC996 and NOZ cells (Figure 3C). Oridonin treatment for $48 \mathrm{~h}$ down-regulated cyclin $\mathrm{A}$ and cyclin B1 and up-regulated cyclin D1, indicating that oridonin induces S-phase arrest in these cells.

\section{Oridonin induces apoptosis of gallbladder cancer cells}

To assess the mechanism underlying oridonin-mediated growth inhibition, oridonin-treated SGC996 and NOZ cells were stained with annexin V-FITC and PI for flow cytometric analysis. Externalization of phosphatidylserine (PS) from the inner leaflet to the outer leaflet of the plasma membrane is a distinct phenomenon of early apoptosis. As annexin V possesses high affinity for PS, apoptotic cells can easily be detected by fluorescently

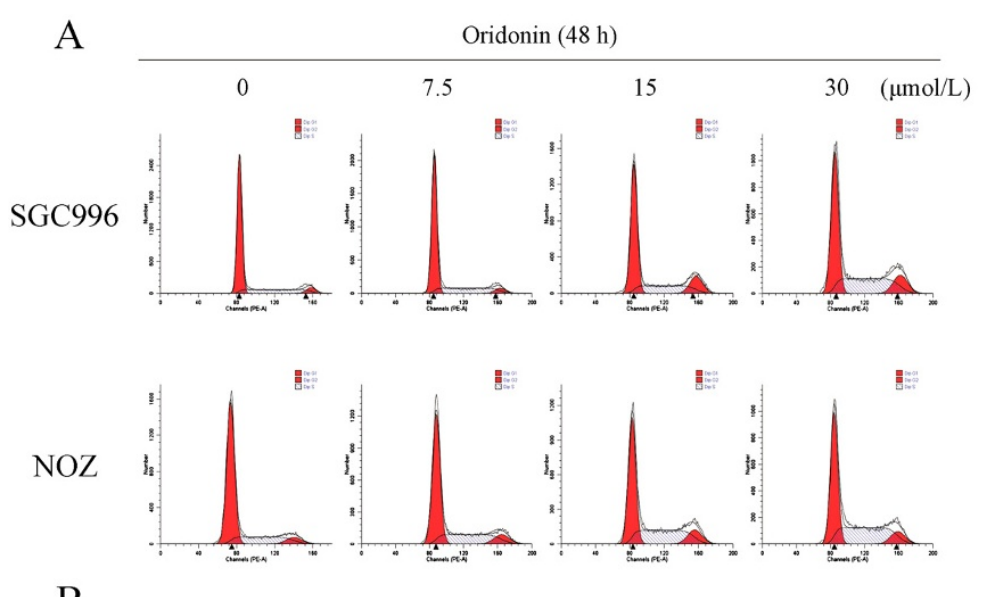

B
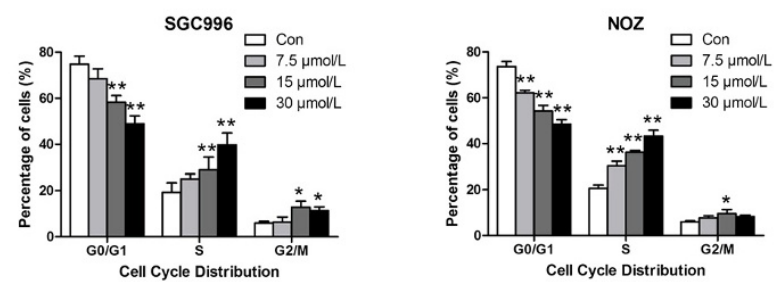

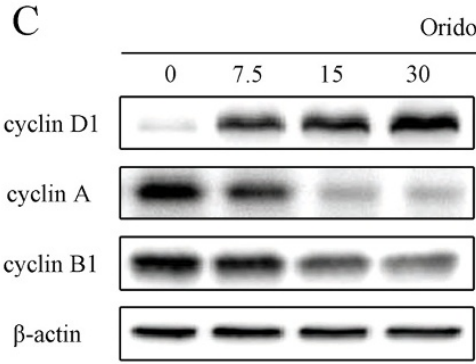

SGC996

Oridonin (48 h)

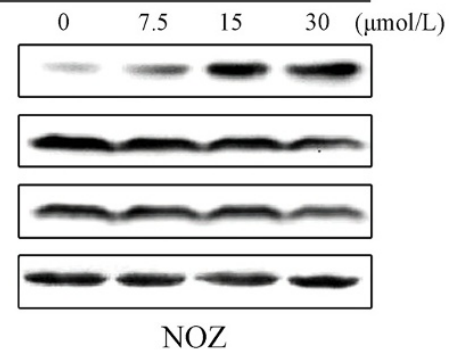

Figure 3 Oridonin induces cell cycle arrest at S-phase and regulates the expression of cell cycle-related proteins in gallbladder cancer cells. SGC996 and NOZ cells were treated with oridonin $(7.5,15$, and $30 \mu \mathrm{mol} / \mathrm{L})$ for $48 \mathrm{~h}$. (A) The cell cycle phases of the treated cells were evaluated by flow cytometry. (B) Data were expressed as mean $\pm S D(n=3)$. (C) The expression levels of cyclin $A$, cyclin B1, and cyclin D1 were measured by western blot analysis, and $\beta$-actin was used as a loading control. Results were representative of 3 independent experiments. ${ }^{*} P<0.05$, ${ }^{* *} P<0.01$ vs. the control group. 
labeling annexin V. In contrast, PI can detect necrotic cells due to its ability to permeate damaged cell membranes. Oridonin treatment induced a dose-dependent increase in both early and late stage apoptosis of SGC996 and NOZ cells (Figure 4A). Oridonin at a concentration of $30 \mu \mathrm{mol} / \mathrm{L}$ had a more significant apoptosis-inducing effect when compared to the number of apoptotic cells in the control group.

Apoptosis was also confirmed by examining the nuclear morphology by Hoechst 33342 staining. The cells in the control group were round and homogeneously stained, whereas oridonin-treated cells showed obvious chromatin condensation and fragmentation (Figure 4C). Moreover, the numbers of apoptotic nuclei containing condensed chromatin increased significantly as the oridonin concentration increased. Based on these morphologic changes, oridonin appeared to cause apoptosis of gallbladder cancer cells.

It is well known that proteins in the caspase family, Bcl-2 family, NF- $\mathrm{kB}$, and PARP play critical roles in the apoptotic process [18-21]. We assessed these apoptosisrelated proteins by western blot analysis. Treatment with oridonin down-regulated Bcl-2, NF- $\mathrm{B}$, and up-regulated cleaved caspase-3, caspase-9, cleaved PARP-1, mitochondrial Bax and cytosol cytochrome $c$ in a dose-dependent manner, which may be responsible, at least in part, for the apoptotic tendency of oridonin-treated SGC996 and NOZ cells (Figure 5A).

\section{Oridonin regulates caspase- $3,-8$ and -9 activation}

The process of apoptosis involves a cascade of proteolytic activity, much of it carried out by caspases. To further characterize the apoptotic pathway activated by oridonin, we determined the kinetics of caspase activation. The activation of caspases in ordoin-treated cells was assessed using colorigenic tetrapeptide substrates, Ac-DEVD-pNA, AcIETD-pNA and Ac-LEHD-pNA, which have been shown to be selective for caspase-3, -8 and caspase-9-like enzymatic activities, respectively. Caspase-3, -8 and -9 activity induced by oridonin at $0,7.5,15$ and $30 \mu \mathrm{mol} / \mathrm{L}$ after $48 \mathrm{~h}$ were measured using caspase-3, -8, -9 activity kit. oridonin induced the activity of both caspase- 3 and -9 in SGC996 and NOZ cells in a dose-dependent manner (Figure $5 \mathrm{~B}$ ). But the activity of caspase- 8 had no obvious changed which manifest that the signal pathway is independent of caspase- 8 regulation.

\section{Oridonin induces disruption of mitochondrial integrity in gallbladder cancer cells}

To investigate mitochondrial membrane potential $(\Delta \Psi \mathrm{m})$ changes induced by oridonin treatment, cells were stained with Rhodamine 123 and staining was detected by flow cytometry. The loss of the $\Delta \Psi \mathrm{m}$ was reflected by a decrease in the intensity of Rhodamine 123 fluorescent staining, which was used to detect mitochondrial membrane integrity. Compared with the control cells, oridonin treatment increased the ratio of Rhodamine 123negative cells from $2.85 \%$ to $69.1 \%$ for SGC996 cells and from $27.6 \%$ to $80.8 \%$ for NOZ cells in a dosedependent manner (Figure 6). These findings suggest that oridonin could reduce mitochondrial membrane potential and induce mitochondrial dysfunction in gallbladder cancer cells.

\section{Oridonin represses the growth of $\mathrm{NOZ}$ cells in vivo}

To determine the antitumor effect of oridonin in vivo, mice bearing NOZ cell tumors were administered oridonin or vehicle (10\% DMSO and 90\% PBS) every 2 days for up to 20 days. The tumors removed from these animals are shown in Figure $7 \mathrm{~A}$ and $7 \mathrm{C}$, and their mean weights and volumes are provided in Figure $7 \mathrm{~B}$ and 7D. There was a marked reduction in tumor volume and tumor weight in mice treated with oridonin compared with control mice, and this reduction was dose dependent (Figure 7). The appearance of the tumors was in agreement with the statistical analysis of tumor volume data, which showed that oridonin treatment significantly inhibited tumor growth.

To determine whether the impact of oridonin on tumor growth inhibition was related to caspase-3, caspase-9, NF$\kappa \mathrm{B}, \mathrm{Bax}, \mathrm{Bcl}-2, \mathrm{PARP}-1$ and cytochrome $c$, we evaluated the levels of these apoptosis-related proteins in the gallbladder tumor tissues by western blot analysis. The results showed down-regulation of Bcl-2 and NF- $\mathrm{KB}$ and up-regulation of cleaved caspase-3, caspase-9, cleaved PARP-1, mitochondrial Bax and cytosol cytochrome $c$ compared to the control group, which was in agreement with the results of the in vitro tests (Figure $7 \mathrm{E}$ ).

\section{Discussion}

Previous studies have shown that oridonin possesses anti-proliferative and apoptotic activities against a variety cancer cells [22]. The results of this study demonstrated for the first time that oridonin decreased the viability of gallbladder cancer cell lines. The data from the MTT assays showed that oridonin inhibited the growth of SGC996 and NOZ cells in a time- and dose-dependent manner (Figure 1). Both the concentration and incubation time affected the cytotoxicity of oridonin. The colony forming assay showed similar results after a longer incubation period (Figure 2). The predominant mode of cell death in these cells was apoptosis, as determined by annexin V-FITC/PI staining (Figure 4A), characteristic changes in the morphology of Hoechst 33342-stained cells (Figure 4C), and cell cycle arrest studies (Figure 3A). Consistent with these in vitro results, treatment of $\mathrm{NOZ}$ xenografts in athymic nude mice with oridonin for 3 weeks significantly decreased the growth of the 


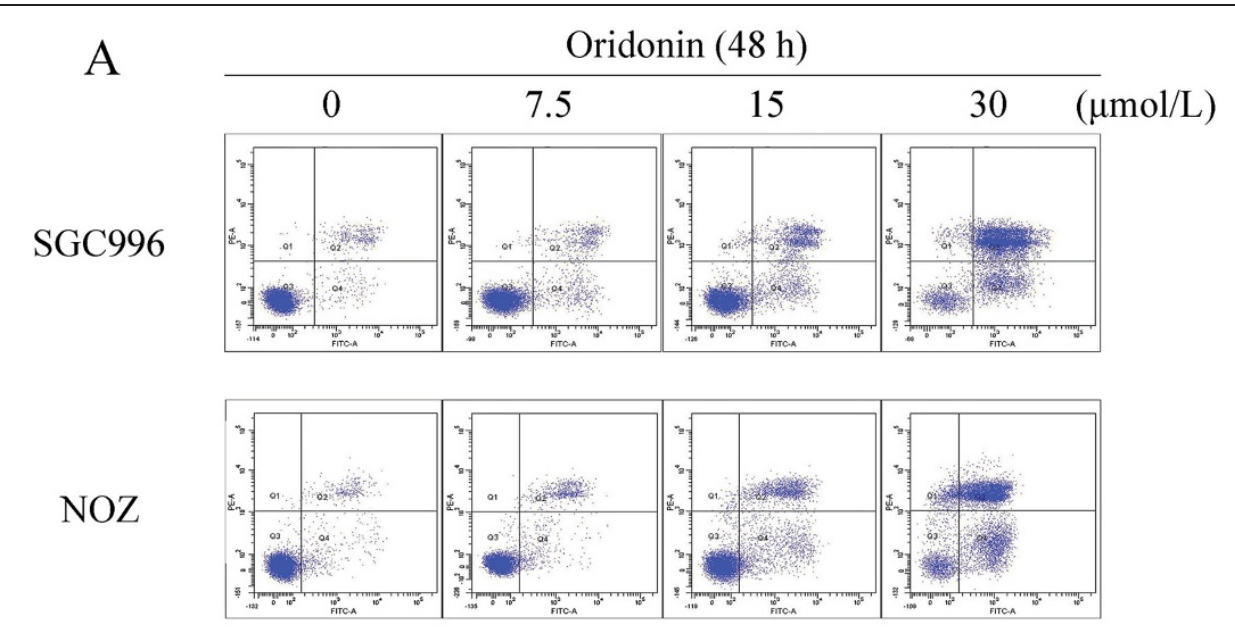

$\mathrm{B}$

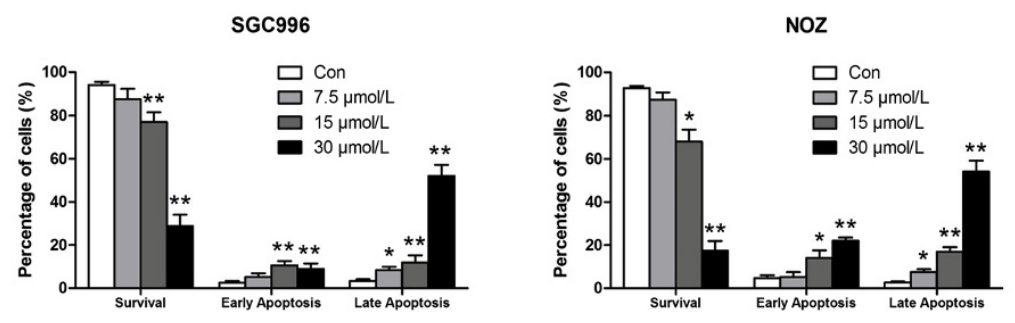

C

Oridonin $(48 \mathrm{~h})$

\begin{tabular}{lllll}
\hline 0 & 7.5 & 15 & $30 \quad(\mu \mathrm{mol} / \mathrm{L})$
\end{tabular}
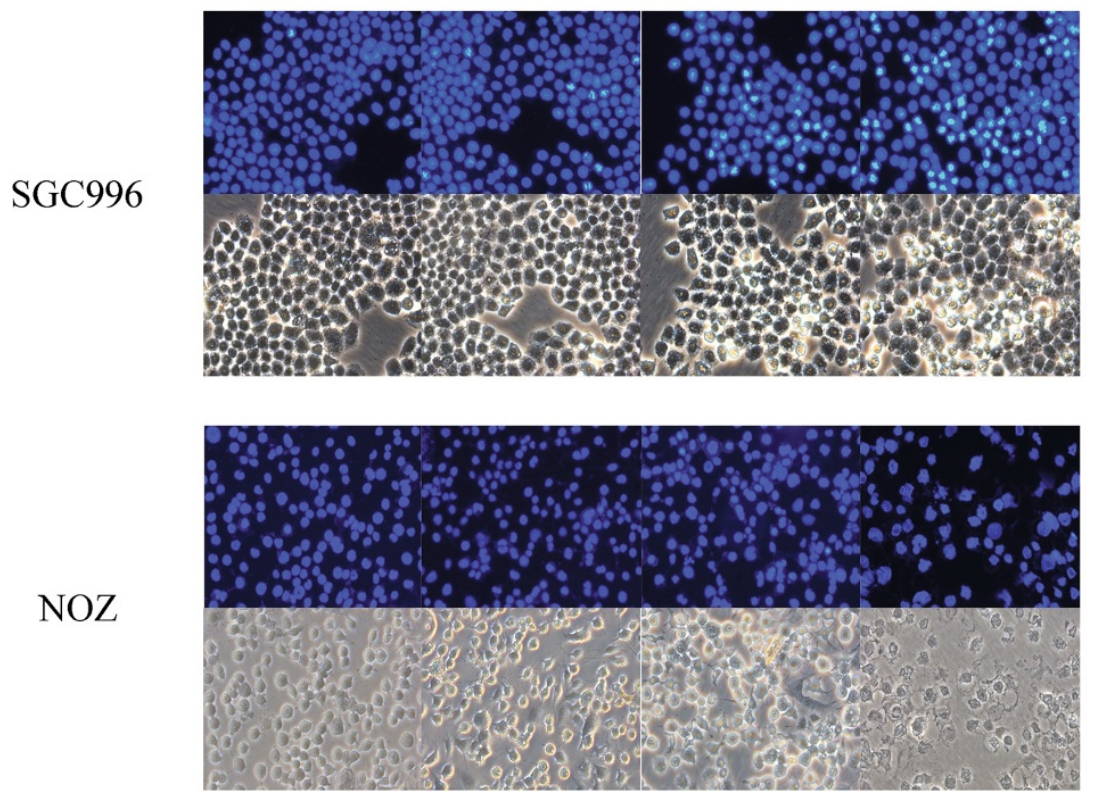

Figure 4 Oridonin induces apoptosis in gallbladder cancer cells. SGC996 and NOZ cells were treated with oridonin $(7.5,15$, and 30 $\mu \mathrm{mol} / \mathrm{L})$ for 48 h. (A) Oridonin-treated SGC996 and NOZ cells were stained with annexin V-FITC/PI and analyzed by flow cytometry. (B) The percentage of apoptotic cells is presented as the mean \pm SD $(n=3)$. (C) Changes in apoptotic nuclear morphology were observed by Hoechst 33342 staining and visualized by fluorescent microscopy. Results shown were representative data from 3 independent experiments. ${ }^{*} P<0.05$, ${ }^{* *} P<0.01$ vs. the control group. 


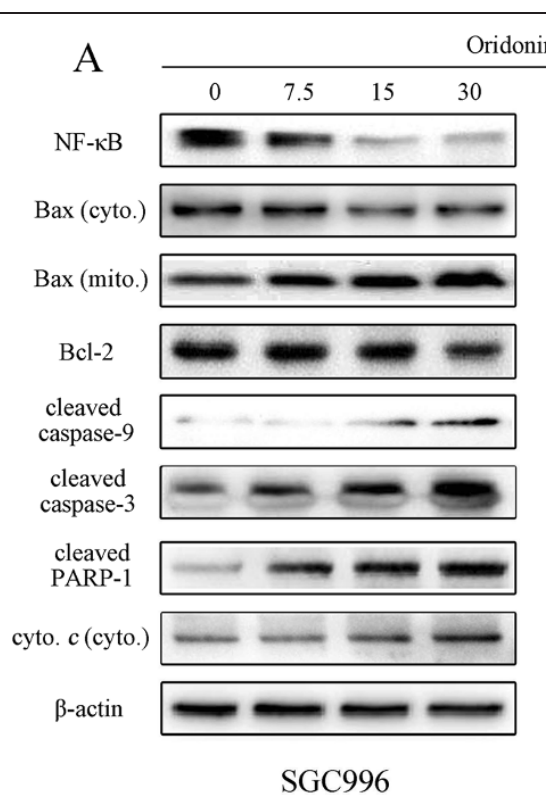

B

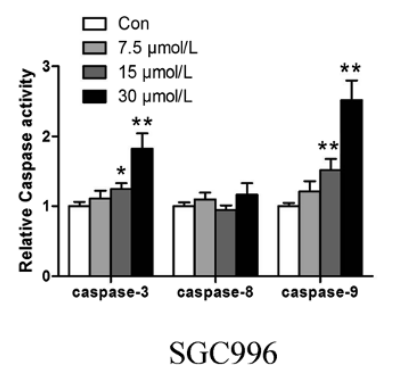

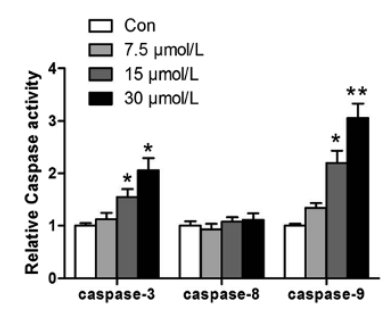

$\mathrm{NOZ}$

Figure 5 Oridonin regulates the expression of apoptosis related proteins and caspases activities in gallbladder cancer cells. SGC996 and NOZ cells were treated with oridonin $(7.5,15$, and 30 mol/L) for 48 h. (A) The expression levels of NF-KB, Bax, Bcl-2, cleaved caspase-9, caspase-3, cleaved PARP-1, cytochrome $c$ were detected by western blot analysis, and $\beta$-actin was used as a loading control. (B) The data of the caspases activities were expressed as mean \pm SD. The results shown were representative data from 3 independent experiments. ${ }^{*} P<0.05$, ${ }^{* *} P<0.01$ vs. the control group.

xenografts (Figure 7). These results provided strong evidence in support of the notion that oridonin has potent apoptotic effects against gallbladder cancer in vitro and in vivo.

It is well known that apoptosis is a programmed process that is essential for the development of most metazoans, and that deregulation of apoptosis is an indicator of cancer [23]. Generally, there are two major apoptosis pathways: the death-receptor-induced extrinsic pathway and the mitochondria-apoptosome-mediated apoptotic intrinsic pathway [24]. Mitochondria play an important role in regulating many cellular functions, and mitochondrial dysfunction has been proposed to be involved in many pathological processes [25]. In the present study, it is worth noting that there were similar levels of annexin-Vpositive and Rhodamine 123-negative cells, which suggests that apoptosis is closely related to or dependent on the loss of $\Delta \Psi \mathrm{m}$ (Figure 6).
In the mitochondrial pathway, NF- $\mathrm{kB}$, a pro-survival transcription factor, controls the inflammatory and immune response as well as other genetic programs that are central to cell proliferation and cell survival and decrease the sensitivity of cancer cells to apoptosis [26]. NF- $\kappa B$ inhibits apoptosis by inhibiting Bcl-2 members and inhibitors of apoptosis [27]. In this study, inhibition of NF-kB nuclear translocation together with the down-regulation of its target Bcl-2 family member genes suggested that activation of NF- $\mathrm{KB}$ was inhibited by oridonin during tumor progression (Figure 5A).

The prime inducers of apoptotic pathways are proapoptotic and anti-apoptotic Bcl-2 family proteins and caspases. During apoptosis, the permeability of the mitochondrial membrane increased, leading to a loss of membrane potential and release of cytochrome $c$ into the cytosol, which binds to apoptotic protease activating 


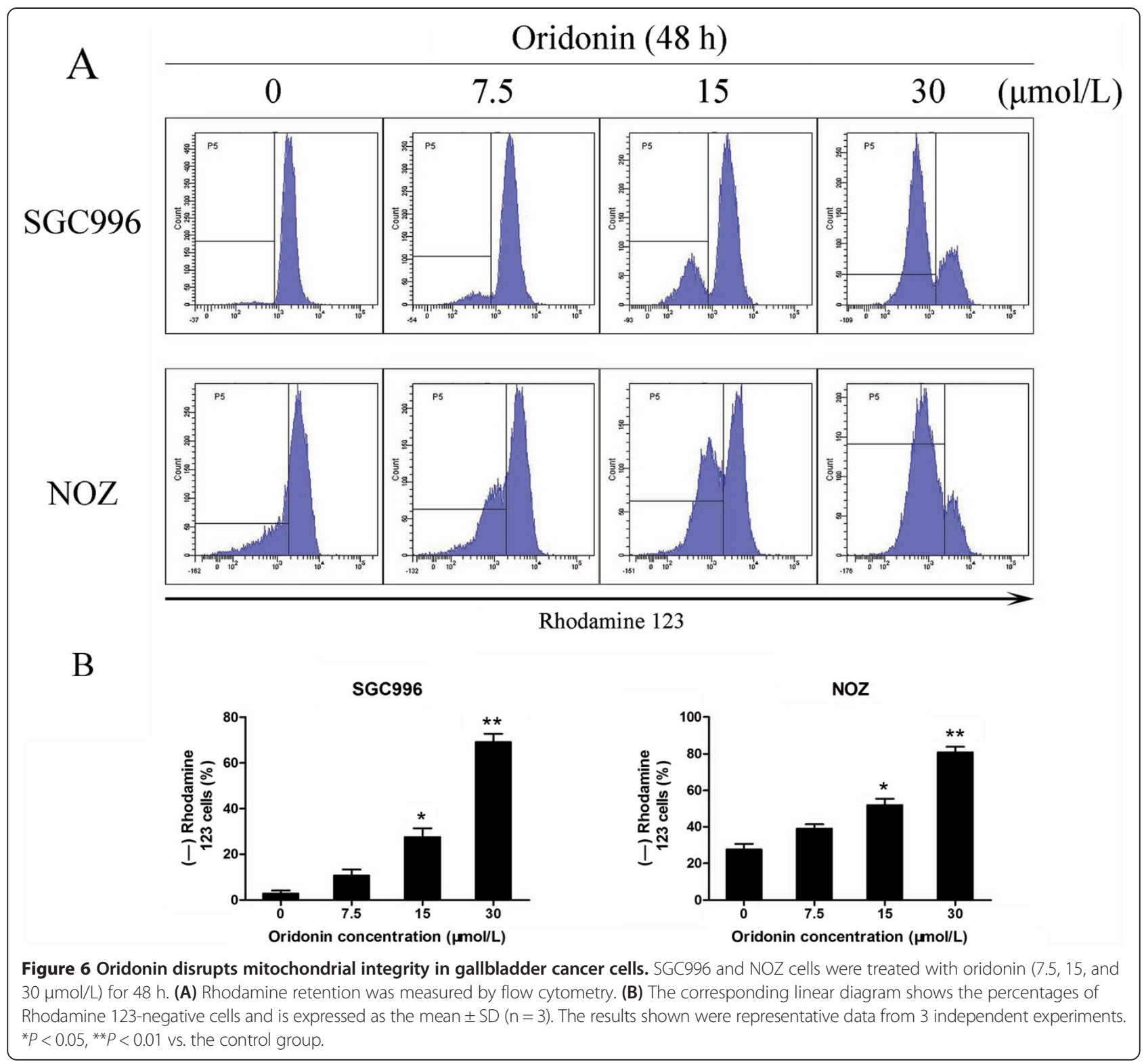

factor-1 (Apaf-1) [28]. The Bcl-2 and Bcl-xL proteins have been identified as anti-apoptotic proteins, which bind to the outer membrane of the mitochondrion and prevent the release of cytochrome $c$ [29]. The proapoptotic members of this family, Bax and Bak, are responsible for permeabilizing the membrane under stress and promoting the release of cytochrome $c$ from the mitochondria [30,31]. It has been suggested that a high Bax to $\mathrm{Bcl}-2$ ratio can cause $\Delta \Psi \mathrm{m}$ collapse, release of cytochrome $c$, and subsequent apoptosis [32]. Our results show that oridonin significantly decreased Bcl-2 and induced the translocation of Bax to the mitochondria with the release of cytochrome $c$ into the cytosol, suggesting that mitochondria are involved in oridonininduced apoptosis (Figure 5A).

Caspases, a family of cysteases, play a crucial role in apoptosis progression, morphological changes, and DNA fragmentation [33]. Two distinct pathways of apoptosis have been identified as mitochondria-initiated apoptosis occurs through caspase-9; the death receptor-mediated pathway requires caspase-8 [34]. Bcl-2 inhibits the apoptotic process and promotes cell survival, and Bax acts within the mitochondria to induce the release of cytochrome $c$, leading to caspase- 9 activation, and subsequent caspase- 3 activation. Caspase- 3 is one of the most important executioner caspases, and it is capable of cleaving many 


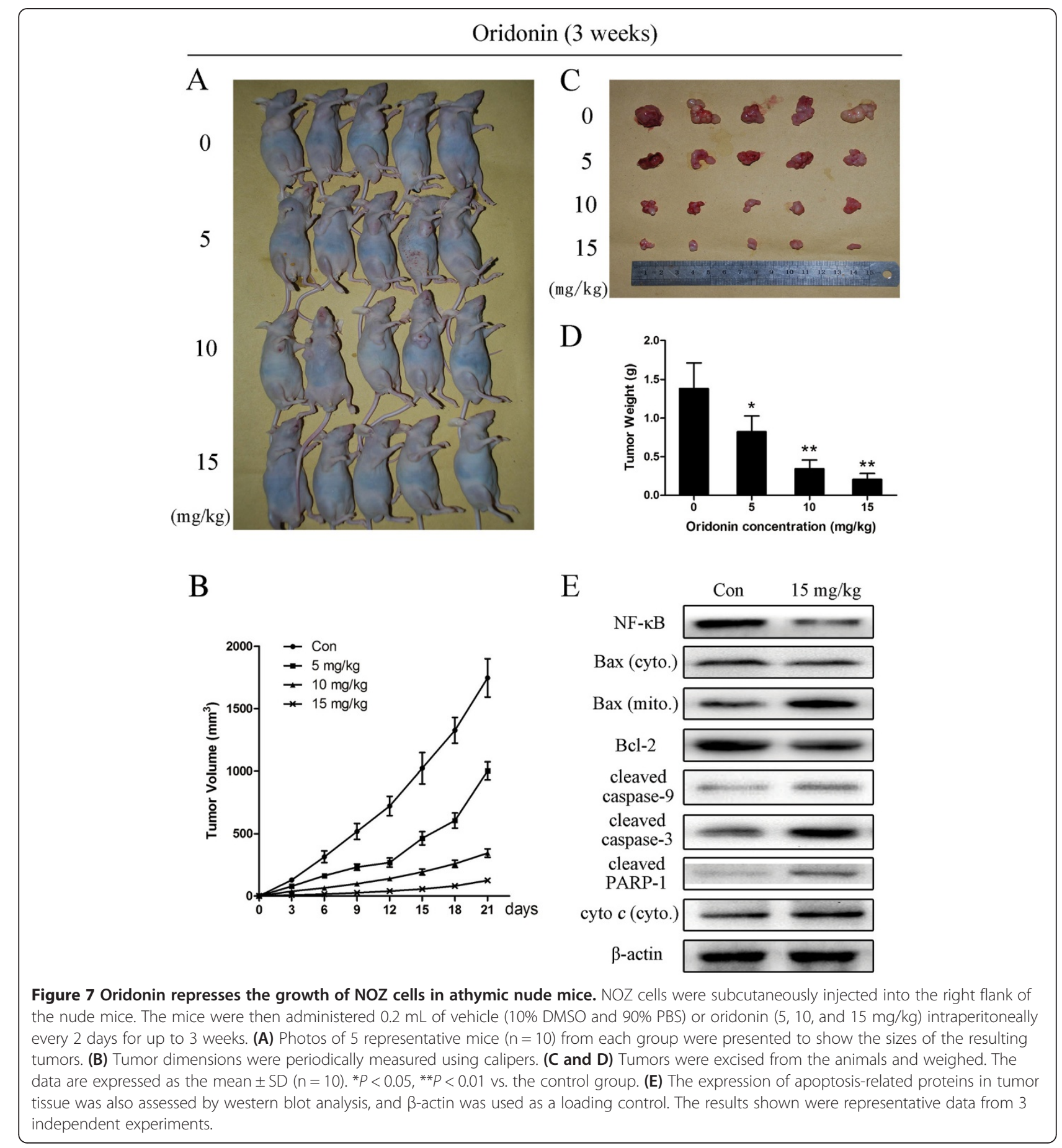

important cellular substrates such as PARP [35]. In our study, oridonin treatment activated caspase- 3 and caspase9, regulated the cleavage of PARP-1 (Figure 5A). Furthermore, ordonin raised the enzymatic activity of caspase-3 and caspase- 9 significantly but not caspase-8 (Figure 5B), which suggested involvement of mitochondrial death pathways in oridonin-induced apoptosis. When we investigated the mechanisms by which oridonin manifests its effects against gallbladder cancer in an animal model, the results were in agreement with those of the in vitro tests (Figure 7E).

Progression through the various phases of the cell cycle is a tightly regulated process involving the various cyclins and cyclin-dependent kinases (Cdks), each of which function at different cell cycle phases [36]. The complex of cyclin A and Cdk2 initiates DNA synthesis 
and progression through S-phase [37]. As suggested by our cell cycle analysis data, oridonin arrested SGC996 and NOZ cells at S-phase (Figure 3A), which might be due to down-regulation of cyclin $\mathrm{A}$ and cyclin $\mathrm{B} 1$ and up-regulation of cyclin D1 (Figure 3C).

\section{Conclusions}

In summary, our study showed that oridonin is a potent growth inhibitor of gallbladder cancer in vitro and in vivo. Growth inhibition was dose-dependent and was related to S-phase arrest. Oridonin also caused a marked increase in apoptosis, which was determined by characteristic morphological changes, increased numbers of apoptotic cells, and the loss of $\Delta \Psi \mathrm{m}$. Furthermore, inhibition of NF- $\mathrm{KB}$ nuclear translocation and an increased $\mathrm{Bax} / \mathrm{Bcl}-2$ ratio was mediated by activated caspase- 3 and caspase-9 and PARP-1 cleavage. Taken together, these observations indicate that the mitochondrial pathway is involved in apoptosis induced by oridonin treatment. Oridonin has potential as a novel anti-tumor therapeutic strategy for the treatment of gallbladder cancer.

\section{Competing interests}

The authors declare that they have no competing interests.

\section{Authors' contributions}

BRF and SYJ were responsible for the design of the experiments, execution of experiments, data statistics, and writing of the manuscript. LTY, JL and HYP participated in performing the experiments, and in the data analysis. TZJ helped in the study design. WH, DQ, CY, MJS, and DQC participated in discussion and data interpretation. WXS, LML, and WWG conceived of the study and revised the manuscript. LYB and GJF were responsible for the funding application, and supervision and management of the project. All authors have contributed to and approved the final manuscript.

\section{Acknowledgements}

This study was supported by National Natural Science Foundation of China (No. 81172026, 81272402, 81301816 and 81172029), National High Technology Research and Development Program (863 Program) (No. 2012AA022606), Foundation for Interdisciplinary research of Shanghai Jiao Tong University (No. YG2011ZD07), Shanghai science and technology commission inter-governmental international cooperation project (No. 12410705900), Shanghai science and technology commission medical-guiding project (No. 12401905800), Program for Changjiang Scholars, Natural Science Research Fundation of Shanghai Jiao Tong University School of Medicine (No. 13XJ10037), Leading Talent program of Shanghai and Specialized Research Fundation for Ph.D Program of Higher Education-Priority Development Field (No. 20130073130014).

\section{Author details \\ ${ }^{1}$ Institute of Biliary Tract Disease, Shanghai Jiao Tong University School of Medicine, No. 1665 Kongjiang Road, Shanghai 200092, China. ${ }^{2}$ Laboratory of General Surgery and Department of General Surgery, Xinhua Hospital, Affiliated to Shanghai Jiao Tong University, School of Medicine, No. 1665 Kongjiang Road, Shanghai 200092, China. ${ }^{3}$ Department of General Surgery, Changshu Hospital, Affiliated to Suzhou University, No.1 Shuyuan Road, Changshu 215500, China.}

Received: 10 November 2013 Accepted: 6 March 2014 Published: 21 March 2014

\section{References}

1. Dong P, He XW, Gu J, Wu WG, Li ML, Yang JH, Zhang L, Ding OC, Lu JH, Mu JS, Chen L, Li SG, Ding LF, Wang JW, Liu YB: Vimentin significantly promoted gallbladder carcinoma metastasis. Chin Med J (Engl) 2011, 124(24):4236-4244.
2. Li M, Shen J, Wu X, Zhang B, Zhang R, Weng H, Ding Q, Tan Z, Gao G, Mu J, Yang J, Shu Y, Bao R, Ding Q, Wu W, Cao Y, Liu Y: Downregulated expression of hepatoma-derived growth factor (HDGF) reduces gallbladder cancer cell proliferation and invasion. Med Oncol 2013, 30(2):587.

3. Tan Z, Zhang S, Li M, Wu X, Weng H, Ding Q, Cao Y, Bao R, Shu Y, Mu J, Ding Q, Wu W, Yang J, Zhang L, Liu Y: Regulation of cell proliferation and migration in gallbladder cancer by zinc finger X-chromosomal protein. Gene 2013, 528(2):261-266.

4. Wu XS, Shi LB, Li ML, Ding Q, Weng H, Wu WG, Cao Y, Bao RF, Shu YJ, Ding QC, Mu JS, Gu J, Dong P, Liu YB: Evaluation of Two Inflammation-Based Prognostic Scores in Patients with Resectable Gallbladder Carcinoma. Ann Surg Oncol 2014, 21(2):449-457.

5. Wang JW, Peng SY, Li JT, Wang Y, Zhang ZP, Cheng Y, Cheng DQ, Weng WH, Wu XS, Fei XZ, Quan ZW, Li JY, Li SG, Liu YB: Identification of metastasisassociated proteins involved in gallbladder carcinoma metastasis by proteomic analysis and functional exploration of chloride intracellular channel 1. Cancer Lett 2009, 281(1):71-81.

6. Liu TY, Tan ZJ, Jiang L, Gu JF, Wu XS, Cao Y, Li ML, Wu KJ, Liu YB: Curcumin induces apoptosis in gallbladder carcinoma cell line GBC-SD cells. Cancer Cell Int 2013, 13(1):64.

7. Sun HD, Huang SX, Han QB: Diterpenoids from Isodon species and their biological activities. Nat Prod Rep 2006, 23(5):673-698.

8. Wang S, Zhong Z, Wan J, Tan W, Wu G, Chen M, Wang Y: Oridonin induces apoptosis, inhibits migration and invasion on highly-metastatic human breast cancer cells. Am J Chin Med 2013, 41(1):177-196.

9. Chen G, Wang K, Yang BY, Tang B, Chen JX, Hua ZC: Synergistic antitumor activity of oridonin and arsenic trioxide on hepatocellular carcinoma cells. Int J Oncol 2012, 40(1):139-147.

10. Gao FH, Hu XH, Li W, Liu H, Zhang YJ, Guo ZY, Xu MH, Wang ST, Jiang B, Liu F, Zhao YZ, Fang Y, Chen FY, Wu YL: Oridonin induces apoptosis and senescence in colorectal cancer cells by increasing histone hyperacetylation and regulation of p16, p21, p27 and c-myc. BMC Cancer 2010, 10:610.

11. Sun KW, Ma YY, Guan TP, Xia YJ, Shao CM, Chen LG, Ren YJ, Yao HB, Yang Q, He $\mathrm{XJ}$ : Oridonin induces apoptosis in gastric cancer through Apaf-1, cytochrome $c$ and caspase-3 signaling pathway. World J Gastroenterol 2012, 18(48):7166-7174.

12. Bu HQ, Luo J, Chen H, Zhang JH, Li HH, Guo HC, Wang ZH, Lin SZ: Oridonin enhances antitumor activity of gemcitabine in pancreatic cancer through MAPK-p38 signaling pathway. Int J Oncol 2012, 41(3):949-958.

13. Ikezoe T, Yang Y, Bandobashi K, Saito T, Takemoto S, Machida H, Togitani K, Koeffler HP, Taguchi H: Oridonin, a diterpenoid purified from Rabdosia rubescens, inhibits the proliferation of cells from lymphoid malignancies in association with blockade of the NF-kappa B signal pathways. Mol Cancer Ther 2005, 4(4):578-586.

14. Chen S, Gao J, Halicka HD, Huang X, Traganos F, Darzynkiewicz Z: The cytostatic and cytotoxic effects of oridonin (Rubescenin), a diterpenoid from Rabdosia rubescens, on tumor cells of different lineage. Int J Oncol 2005, 26(3):579-588.

15. Cui Q, Yu JH, Wu JN, Tashiro S, Onodera S, Minami M, Ikejima T: P53-mediated cell cycle arrest and apoptosis through a caspase-3-independent, but caspase-9-dependent pathway in oridonin-treated MCF-7 human breast cancer cells. Acta Pharmacol Sin 2007, 28(7):1057-1066.

16. Jin S, Shen JN, Wang J, Huang G, Zhou JG: Oridonin induced apoptosis through Akt and MAPKs signaling pathways in human osteosarcoma cells. Cancer Biol Ther 2007, 6(2):261-268.

17. Saris NE, Teplova W, Odinokova IV, Azarashvily TS: Interference of calmidazolium with measurement of mitochondrial membrane potential using the tetraphenylphosphonium electrode or the fluorescent probe rhodamine 123. Anal Biochem 2004, 328(2):109-112.

18. Rodriguez-Vargas JM, Ruiz-Magana MJ, Ruiz-Ruiz C, Majuelos-Melguizo J, Peralta-Leal A, Rodriguez MI, Munoz-Gamez JA, de Almodovar MR, Siles E, Rivas AL, Jaattela M, Oliver FJ: ROS-induced DNA damage and PARP-1 are required for optimal induction of starvation-induced autophagy. Cell Res 2012, 22(7):1181-1198.

19. LV H, Li Y, Du H, Fang J, Song X, Zhang J: The Synthetic Compound Norcantharidin Induced Apoptosis in Mantle Cell Lymphoma In Vivo and In Vitro through the PI3K-Akt-NF- kappa B Signaling Pathway. Evid Based Complement Alternat Med 2013, 2013:461487.

20. She EX, Hao Z: A novel piperazine derivative potently induces caspasedependent apoptosis of cancer cells via inhibition of multiple cancer signaling pathways. Am J Trans/ Res 2013, 5(6):622-633. 
21. Du L, Mei HF, Yin X, Xing YQ: Delayed growth of glioma by a polysaccharide from Aster tataricus involve upregulation of $\mathrm{Bax} / \mathrm{BCl}-2$ ratio, activation of caspase-3/8/9, and downregulation of the Akt. Tumour Biol 2013: [Epub ahead of print]

22. Ikezoe T, Chen SS, Tong XJ, Heber D, Taguchi H, Koeffler HP: Oridonin induces growth inhibition and apoptosis of a variety of human cancer cells. Int J Oncol 2003, 23(4):1187-1193.

23. Kang N, Zhang JH, Qiu F, Tashiro S, Onodera S, Ikejima T: Inhibition of EGFR signaling augments oridonin-induced apoptosis in human laryngeal cancer cells via enhancing oxidative stress coincident with activation of both the intrinsic and extrinsic apoptotic pathways. Cancer Lett 2010, 294(2):147-158.

24. Hu W, Kavanagh JJ: Anticancer therapy targeting the apoptotic pathway. Lancet Oncol 2003, 4(12):721-729.

25. Green DR, Reed JC: Mitochondria and apoptosis. Science 1998, 281 (5381):1309-1312.

26. Scheidereit C: IkappaB kinase complexes: gateways to NF-kappaB activation and transcription. Oncogene 2006, 25(51):6685-6705.

27. Cheng Y, Qiu F, Ye YC, Guo ZM, Tashiro S, Onodera S, Ikejima T: Autophagy inhibits reactive oxygen species-mediated apoptosis via activating p38-nuclear factor-kappa B survival pathways in oridonin-treated murine fibrosarcoma L929 cells. FEBS J 2009, 276(5):1291-1306.

28. Liu Y, Shi QF, Qi M, Tashiro S, Onodera S, Ikejima T: Interruption of hepatocyte growth factor signaling augmented oridonin-induced death in human non-small cell lung cancer A549 cells via c-met-nuclear factor-kappaBcyclooxygenase-2 and c-Met-Bcl-2-caspase-3 pathways. Biol Pharm Bull 2012, 35(7):1150-1158

29. Pal S, Pal PB, Das J, Sil PC: Involvement of both intrinsic and extrinsic pathways in hepatoprotection of arjunolic acid against cadmium induced acute damage in vitro. Toxicology 2011, 283(2-3):129-139.

30. Ewings KE, Wiggins CM, Cook SJ: Bim and the pro-survival $\mathrm{BCl}-2$ proteins: opposites attract, ERK repels. Cell Cycle 2007, 6(18):2236-2240.

31. Das A, Banik NL, Patel SJ, Ray SK: Dexamethasone protected human glioblastoma U87MG cells from temozolomide induced apoptosis by maintaining Bax:Bcl-2 ratio and preventing proteolytic activities. Mol Cancer 2004, 3(1):36.

32. Zhang YH, Wu YL, Tashiro S, Onodera S, Ikejima T: Reactive oxygen species contribute to oridonin-induced apoptosis and autophagy in human cervical carcinoma HeLa cells. Acta Pharmacol Sin 2011, 32(10):1266-1275.

33. Kagawa S, Gu J, Honda T, McDonnell TJ, Swisher SG, Roth JA, Fang B: Deficiency of caspase- 3 in MCF7 cells blocks Bax-mediated nuclear fragmentation but not cell death. Clin Cancer Res 2001, 7(5):1474-1480.

34. Mao WP, Ye JL, Guan ZB, Zhao JM, Zhang C, Zhang NN, Jiang P, Tian T: Cadmium induces apoptosis in human embryonic kidney (HEK) 293 cells by caspase-dependent and -independent pathways acting on mitochondria. Toxicol In Vitro 2007, 21(3):343-354.

35. Wang J, Wu A, Xu Y, Liu J, Qian X: M(2)-A induces apoptosis and G(2)-M arrest via inhibiting PI3K/Akt pathway in HL60 cells. Cancer Lett 2009, 283(2):193-202.

36. Bloom J, Cross FR: Multiple levels of cyclin specificity in cell-cycle control. Nat Rev Mol Cell Biol 2007, 8(2):149-160.

37. Moon J, Yu SJ, Kim HS, Sohn J: Induction of G(1) cell cycle arrest and p27 (KIP1) increase by panaxydol isolated from Panax ginseng. Biochem Pharmacol 2000, 59(9):1109-1116.

doi:10.1186/1471-2407-14-217

Cite this article as: Bao et al:: Oridonin induces apoptosis and cell cycle arrest of gallbladder cancer cells via the mitochondrial pathway. BMC Cancer 2014 14:217.

\section{Submit your next manuscript to BioMed Central and take full advantage of:}

- Convenient online submission

- Thorough peer review

- No space constraints or color figure charges

- Immediate publication on acceptance

- Inclusion in PubMed, CAS, Scopus and Google Scholar

- Research which is freely available for redistribution

Submit your manuscript at www.biomedcentral.com/submit 